\title{
๑ INFLUÊNCIA DOS GRUPOS DE PRESSÃO NA LEGISLAÇÃO PENAL BRASILEIRA
}

\author{
THE INFLUENCE OF PRESSURE GROUPS IN BRAZILIAN CRIMINAL \\ LEGISLATION
}

\author{
(iD Osvaldo Capelari Junior \\ Universidade Nove de Julho (Uninove) \\ Procurador Regional da República (PRR $3^{\mathrm{a}}$ Região) \\ cap.neto12@gmail.com
}

\begin{abstract}
Marcelo Navarro Ribeiro Dantas Universidade Nove de Julho (Uninove) Doutor em Direito Professor Associado do Curso de Direito da Universidade Federal do Rio Grande do Norte, ora em colaboração com a Faculdade de Direito da Universidade de Brasília. Professor Emérito da Universidade Nove de Julho. Ministro do Superior Tribunal de Justiça Brasília/Distrito Federal/Brasil mnrdantas@uol.com.br
\end{abstract}

Resumo: O presente artigo propõe a compreensão do que são grupos de pressão e como esses grupos agem ao influenciar o processo legislativo no Brasil e no mundo, explorando, ainda, o recorte social e jurídico da efetividade de sua ação, no que concerne à legislação criminal vigente no país. Nesse sentido, é indispensável esclarecer que o Direito Penal se orienta, quando da produção legislativa, em conformidade com uma (pre)suposta racionalidade relacionada, ex ante, a interesses setoriais.

Palavras-chave: direito penal; processo legislativo; grupos de pressão.

Abstract: This article proposes an understanding of what are pressure groups and how these groups act to influence the legislative process in Brazil and in the world, also exploring the social and legal framework of the effectiveness of their action, with regard to the criminal legislation in force in the country. In this sense, it is essential to clarify that the Criminal Law is guided, when producing legislation, in accordance with a (supposed) rationality related, $e x$ ante, to sectorial interests.

Keywords: criminal law; legislative process; pressure groups.

CAPELARI JUNIOR, Osvaldo; DANTAS, Marcelo Navarro Ribeiro. A influência dos grupos de pressão na legislação penal brasileira. Revista Thesis Juris - RTJ, São Paulo, v. 10, n. 2, p. 338-356, jul./dez. 2021. http://doi.org/10.5585/rtj.v10i2.20939. 


\section{Introdução}

O legislador não é infenso aos grupos de pressão, conforme se quer demonstrar, pois muito pelo contrário - , a lei penal, conquanto forjada pela política oficial do Estado, encontrase também sujeita à atuação de determinados segmentos sociais organizados e dotados de poder, seja político, econômico, de comunicação, religioso, burocrático ou institucional, os quais perseguem interesses os mais variados, capazes de influir decisiva e importantemente nos processos de formação da vontade legislativa. Esse fenômeno, no Direito Penal e, por evidente, na Política Criminal, constitui, muitas vezes o suporte necessário e suficiente para neutralizar os comportamentos que discrepam dos padrões estabelecidos por esses estamentos, mediante proibições que findam passando a constar nos mandamentos da legislação penal.

Portanto, é indispensável compreender os esforços dos grupos de pressão para a manutenção do status quo, devendo-se anotar que o receio da pena criminal é, sem dúvida, o recurso mais efetivo para coibir comportamentos socialmente censurados. Além do mais, restará claro que, em campo diametralmente oposto, quando o comportamento desviante é resultado da ação dos estratos superiores da sociedade, percebe-se que operam vários mecanismos que vão desde a produção da norma à persecução penal, cuja finalidade é subtrair tais ações criminosas das instâncias próprias de controle.

Nesse sentido, o presente artigo propõe a compreensão do que são grupos de pressão e como esses grupos agem ao influenciar o processo legislativo no Brasil e no mundo, explorando, ainda, o recorte social e jurídico da efetividade de sua ação, no que concerne à legislação criminal vigente no país. Com efeito, é indispensável esclarecer que o Direito Penal se orienta, quando da produção legislativa, em conformidade com uma (pré)suposta racionalidade relacionada, ex ante, a interesses setoriais.

E assim é que, nos dias atuais, o reflexo das proposições legislativas que tramitam perante o Poder Legislativo e das correlatas políticas públicas delas derivadas, levando em consideração, principalmente, a popularização dos meios de comunicação, especialmente as redes sociais que passaram a escrutinar (a)criticamente os múltiplos eventos políticos ocorridos no Brasil, a partir da remoção do entulho autoritário - legado de um período de repressão do pensamento objetivado na opinião e expressão —, vêm gerando uma série de reações em grupos sociais dos mais variados espectros, conquanto seja sabido que a produção e distribuição da informação é, em realidade, por vezes, enviesada, desde que chancelada pelos grandes grupos de comunicação. Tudo isso é propiciado por uma democracia em diversos aspectos meramente formal, em que as instituições parecem funcionar, mas é possível deduzir que a livre circulação 
de ideias é com frequência distorcida pelos principais veículos de comunicação.

Por outro lado, é bem verdade que as redes sociais ingressaram no debate público sobre os rumos do Direito Penal e suas implicações no tecido social, sendo oportuno lembrar que dada a baixa educação da população em geral, inclusive dos ditos formadores de opinião, as expressões que são objetivação da liberdade de pensamento, constitucionalmente entronizada, resultam, no final das contas, em ideias que contrastam com a pretensa racionalidade do legislador penal.

Entretanto, nem todos os grupos sociais logram êxito em transmitir ao Poder Legislativo a defesa de seus interesses, embora alguns deles emerjam como grupos de pressão, delineando uma trajetória jurídico-social que, de certo modo, guia o processo legislativo e o desenvolvimento de um Direito Penal pouco democrático.

Noutro giro, é de rigor tratar da concepção de "grupos de pressão" no plano da sociologia jurídica, compreendendo sua diferença para os grupos de interesse e de que modo estes dois tipos de agrupamentos ou organizações de pessoas interessam ao estudo da Sociologia Jurídica e do Direito, em particular do Direito Penal.

A seguir, tratar-se-á da relação entre os grupos de pressão e o Direito Penal, além do que será descrita de modo que se possa perceber, com melhor clareza, o modo como se opera a influência dos primeiros sobre o segundo, para, depois disso, então, passar-se a analisar a atuação desses grupos nas diversas fases do processo legislativo.

Por fim, serão analisados casos em que os grupos de pressão tiveram papel relevante para a construção do Direito através da sua influência no processo legislativo, por meio de casos de ampla notoriedade no mundo e no Brasil, permitindo, assim, uma apreciação mais tangível do tipo de influência exercido por esses grupos sobre o modo como a sociedade se organiza por meio da política e das normas jurídicas.

O presente artigo se dedica, então, a compreender os grupos de pressão e analisar, qualitativamente, o seu impacto na legislação vigente no Brasil, passando por uma revisão conceitual e por um estudo de amostragem de casos célebres em que a atuação destes grupos exerceu fundamental influência nas conformidades do Direito Penal brasileiro.

\section{Grupos de pressão e sociologia jurídica}

Segundo o Dicionário de Ciências Humanas de Dortier (2010, p. 257): “Grupos de pressão, em ciência política, designam organizações cujo objetivo, a função, não é como partidos políticos, a tomada e o exercício do poder, mas a defesa de uma causa junto a 
autoridades políticas e administrativas".

A definição não discrepa da elaborada por Pereira ${ }^{(1999, \text { p. 04) }}$, pois este autor, em seu artigo intitulado "Governabilidade, grupos de pressão e o papel do Estado", exclui dos grupos de interesse os partidos políticos, por várias razões, dentre os quais o fato de os partidos políticos exercerem um papel dentro do modelo constitucional específico, além de estar consagrado institucionalmente na Constituição de muitos países, apresentando um paradigma ideal de sociedade, uma visão mais ou menos articulada de uma multiplicidade dos problemas sociais. Logo, diante de uma característica intrínseca relativa a uma cosmovisão difusa, diante das contingências de compartilhar o exercício do poder do Estado, mediante pautas submetidas ao escrutínio do eleitor e do cidadão, resta claro que os partidos políticos não têm a pretensão e nem poderiam - de assumir uma causa particular como pauta ou agenda de atuação que encontre eco em seus fins institucionais.

Por outro lado, Pereira (1999, p. 05) esclarece que há uma distinção entre grupos de interesse e grupos de pressão. Para ele, genericamente, num dado momento, os grupos de pressão são um subconjunto dos grupos de interesse que visam a pressionar qualquer instância do poder político a alterar suas plataformas num sentido favorável às posições propostas pelo grupo, ou mantê-las, caso elas sejam convergentes com os interesses do grupo. Cuida-se, pois, de uma visão dinâmica dos grupos de pressão.

De todo modo, o ponto de intersecção entre grupos de interesse e de pressão é que eles operam em interesses seccionais, denotando a ausência de uma pauta de reivindicação orgânica ou difusa. Têm legitimidade para atuar de forma particular, de resto seu atributo mais significativo.

No Direito Penal, ou, mais rigorosamente dizendo, na ciência penal, os grupos de interesse merecem atenção da sociologia jurídico-penal, tanto que Baratta (2002, p. 22), lecionando sobre o objeto da matéria, contempla que, numa de suas vertentes, esta abarca o estudo da ação direta ou indireta de grupos de interesse na formação e aplicação do direito, como, também, a reação social ao comportamento desviante, enquanto precede e integra, como controle social não institucional, o controle social do desvio, por meio do direito e dos órgãos oficiais de sua aplicação. Percebe-se, nessa perspectiva, que a atuação dos grupos de pressão perpassa a atuação legislativa e atinge as agências de controle do desvio.

Portanto, a matéria relacionada, no sentido mais geral, aos grupos de interesses e, no particular, aos grupos de pressão, é de relevância teórica e prática para a ciência penal, sobretudo para que ela possa discutir a legitimidade da norma penal ou, como se diz, sua racionalidade ética. 
Posto isso, passemos à análise da relação da criminologia e da dogmática jurídico-penal, a fim de apreender e aprender o que se passa nos estertores de saberes cujas partes, não raramente, permanecem desunidas nos manuais de direito penal, sem reconhecimento da autonomia de um saber criminológico e um saber normativo e sua mútua interdependência, missão que resulta numa estratégia deliberada, cujo objetivo é camuflar a base de problemas sociais pungentes e determinantes em relação à produção da norma e da política pública de segurança, à custa de sua pretensa neutralidade científica.

\section{Grupos de pressão e direito penal}

Na ciência penal, a política criminal, segundo Bergalli, Bustos e Miralles (2015, p. 46), implica a estratégia adotada dentro do Estado a respeito da criminalidade e de seu controle, contando com o auxílio da criminologia e com base em seu material, a fim de orientar seu modo de atuação.

Em sucinta abordagem, Santos (2006, p. 04) afirma que o Código Penal, estatuto que define crimes e prevê as consequências jurídicas para o fato delituoso, é o centro do programa de política penal do Estado para o controle da criminalidade. Entretanto, adverte que, por detrás desta prévia declaração de interesse da classe hegemônica, há interesses sub-reptícios, ocultos ou mascarados e, mesmo o operador do direito, acostumado à neutralidade da dogmática jurídica e a sua vocação estática, não consegue, por isso mesmo, captar esse estado de coisas, porque, se tomasse uma postura crítica, não se distanciando do método de estudo a gênese do delito, das instituições de controle e de sua dinâmica na interação nas relações sociais, compreenderia de forma mais abrangente e, portanto, se portaria, diante das normas produzidas pelo Estado, com uma visão mais humanizada em relação às pessoas que compõem o seleto grupo arregimentado pelas malhas, sempre mais largas, da lei penal.

A visão mais humanizada seria traduzida na compreensão das condições materiais da vida social e na percepção de que os sistemas jurídicos e políticos de controle social estão a serviço de grupos hegemônicas, com a consequente exclusão ou redução dos interesses e necessidades daqueles socialmente subordinados (SANTOS, 2006, p. 07).

E, nesse sentido, Santos (2006, p. 6-8) esclarece que, tomada a decisão pela análise dinâmica da sociedade e do Estado, somente a sociologia jurídico-penal pode fornecer subsídios para compreensão do fenômeno e a definição dos objetivos reais do Direito Penal, permitindo desvelar muito do seu significado como uma estratégia de controle social nas sociedades capitalistas, estruturadas em classes antagônicas pela sua posição nas relações de produção e de 
circulação da vida material.

Nesse formato, Santos (2006, p. 6-7) relaciona os proprietários do capital e possuidores da força de trabalho, redundando numa intersecção - e em situações-limite de conflito - entre todos os fenômenos econômicos da base econômica e das instituições de controle jurídico e político do Estado.

Como o Direito e o Estado não se limitam às funções reais de instituição e reprodução das relações sociais, emergem, a partir disso, funções ilusórias de encobrimento da natureza dessas relações sociais. Por isso, devem ser distinguidos os objetivos declarados do Direito Penal, que produzem uma aparência de neutralidade do sistema de justiça criminal, orientado na pesquisa exclusiva ao nível da lei penal, única fonte formal do Direito Penal, noção, no entanto, dissolvida pelo estudo das fontes materiais do ordenamento jurídico, centrada no modo de produção da vida material, que fundamentam interesses, necessidades e valores das classes sociais dominantes das relações de produção e hegemônicas do poder político do Estado (SANTOS, 2006, p. 07)

Propõe-se, portanto, uma observação dos fatos em sociedade de forma mais real, realçando o papel do Direito Penal e das instituições de controle na seleção do grupo de pessoas alcançadas pela lei penal e, no extremo, na composição da instituição penitenciária.

Dito em outras palavras, o discurso real, fundado na lógica material (modo de produção), em contraposição ao discurso plasmado na lógica formal (a lei e o mito da igualdade no Direito Penal) esclarece, para quem queira entender ou se esforce, nesse sentido, a formação econômica das classes sociais no terreno das ideologias, rompendo, assim, a opacidade do real produzida pelo discurso oficial dos objetivos declarados do direito penal (SANTOS, 2006, p. 7-8).

Do contrário, a análise conjunta dos saberes, que pressupõe a sociologia jurídico-penal, passa a ser um enfado e, mesmo nos ambientes de estudo ou acadêmico, não se logrou, salvo com honrosas exceções, desprender-se do método de encobrimento da real dimensão social e política da ciência penal.

Na perspectiva do discurso dos objetivos declarados, Santos (2006, p. 10) alude ao fato de o sistema de justiça criminal realizar a função declarada de garantir uma ordem social justa, protegendo os bens jurídicos gerais, promovendo o bem comum.

Entretanto, essa premissa é absolutamente falsa se nos debruçarmos sobre a constatação empírica dos indivíduos selecionados (ou recrutados) nos estratos inferiores da sociedade que, de fato, são levados às barras da justiça criminal e efetivamente punidos, em contraste com a delinquência de colarinho branco, socializada, com fortes ligações com a classe dominante e que, por isso, escapa à persecução penal, gerando um efeito denominado cifra oculta, que pode 
ser conceituada como aquela que não consta das estatísticas dos órgãos de controles (Polícia, Ministério Público e Justiça Criminal).

Isso provocou nas análises dos especialistas um olhar para as instituições de controle, substituindo o enfoque de causa do delito e mesmo o etiológico, fundado em pesquisas anatômicas de pessoas criminosas. Nesse último caso, percebe-se um acolhimento da filosofia determinista, conquanto Carrara (2002, p. 52), a seu tempo, na infância da dogmática penal e de um sistema mais abrangente de compreensão da ciência penal, tenha censurado os arautos de tal pensamento extramente reacionário e estigmatizante. Não sem razão escreveu: quando um magistrado reconhece que o réu cedeu a uma força irresistível, deve absolvê-lo, e o absolve. Ora, essa sentença exalta o livre-arbítrio como refutação da necessidade que impele o sujeito ao delito. Em síntese, o homem, como ser racional, tem a faculdade de escolher, num leque de possibilidades, qual o sentido de sua ação e a refletir sobre sua responsabilidade.

Por outro lado, Baratta (2002, p. 101) aduz que foi mérito da teoria do etiquetamento (labeling approach) que a sociologia criminal influenciou na percepção acerca do deslocamento do ponto de partida, do comportamento desviante para os mecanismos de reação e de seleção da população criminosa, elegendo dois aspectos: a criminalidade de colarinho branco; a cifra negra da criminalidade e a crítica das estatísticas oficiais.

Sobre a criminalidade de colarinho branco, Baratta (2002, p. 101), secundado pelos estudos de Sutherland, baseado em dados extraídos das estatísticas de vários órgãos americanos competentes em matéria de economia e comércio, concluiu o quão surpreendentes eram as infrações a normas gerais realizadas, neste setor, por pessoas colocadas em posição de prestígio social, não sendo, isso, um fenômeno, ao nível criminal, confinado aos Estados Unidos da América, mas de todas as sociedades de capitalismo avançado. E, sobre a cifra negra, extrai-se que a influência da ligação com a classe política e os operadores econômicos privados, leva a que esse tipo de criminalidade, mesmo sendo abstratamente prevista pela lei penal, seja escassamente perseguida.

Cifra negra (zona obscura, dark number ou chiffre noir) refere-se, portanto, à proporção, de resto relevante, de crimes não solucionados ou punidos, desconhecida oficialmente, escapando, como se disse, das estatísticas penais e, adicionando-se à impunidade da delinquência de colarinho branco, o que revela a seletividade ou eleição de ocorrências e de infratores da lei penal que, como se sabe, alcança muito mais os desfavorecidos econômica e socialmente.

Cuida-se, portanto, de uma desmistificação da igualdade no Direito Penal, fundado na lógica formal gerada pela percepção da relação capital-trabalho e da dominação ou relação entre 
opressores e oprimidos.

Noutro ângulo, em relação aos indivíduos selecionados pelo sistema penal, Baratta (2002, p. 167) aponta que o cárcere representa a ponta do iceberg que é o sistema penal burguês, o momento culminante de um processo de seleção que começa antes da intervenção do sistema penal, com a discriminação social e escolar, com a intervenção dos institutos de controle do desvio de menores, da assistência social etc.

Este artigo procurará demonstrar que, ao menos nos casos colacionados, os grupos de pressão jamais enfrentaram a criminalidade de colarinho branco - e quando o fizeram, não lograram alcançá-la pela lei penal —, umbilicalmente ligada à elite, termo estudado desde Pareto e Mosca, que apenas reforçaram, ainda que de forma indireta, com seus estudos concentrados na elite governamental ou elite política, que o sistema penal com a formulação de tipos legais de crime alcança, via de regra, a clássica clientela do sistema penal formada pelos desfavorecidos econômica e socialmente.

Em realidade, ajusta-se ao que foi até aqui discorrido a lição de Coenen-Huther (2004, p. 21), para quem:

\begin{abstract}
A distinção, efetuada por Pareto, entre elite governamental e elite não governamental, parece indicar um interesse mais marcado pela elite política do que pelas outras elites. A prioridade assim acordada à elite política reencontra-se noutros teóricos ulteriores. Esta atenção particular não parece derivar de uma sobrevalorização do político mas antes da ideia de que a elite política dispõe do máximo poder na sociedade (CliffordVaughan, 1960, p. 320). Tudo isto foi objeto de controvérsias que não têm fim à vista. $\mathrm{Na}$ realidade, podemos defender esta ideia fundamentando-nos na noção weberiana de monopólio da violência legítima. Mas podemos sugerir, de igual modo, que outras elites - a começar pela elite econômica — não tem necessidade de recorrer à força porque dispõe de outros meios de influência à sua disposição. Nesta perspectiva, o poder da classe política seria um poder de fachada, atrás do qual se dissimulam outras formas de poder.
\end{abstract}

Em adição, é de rigor lembrar que Perissinotto (2009, p. 170-171) procurou abrandar o que para ele era uma falsa dicotomia entre os conceitos de elite e classe dominante, apoiado nos estudos de Tom Bottomore e Ralph Miliband, aduzindo que eles aceitavam o termo elite como sociologicamente válido, desde que submetido à ótica marxista. A distinção, desse modo, era pouco frutífera e poderia trazer ganhos analíticos.

Posto isso, no presente artigo, em que pese reconhecermos o abismo criado pelas teorias das elites e das teorias materialistas históricas, força reconhecer que, para a abordagem, ao menos no que toca à ausência ou muito menor incidência de punição dos estratos superiores, é um denominador comum entre os conceitos.

Retomando a sociologia jurídico-penal, Baratta (2002, p. 162), ao discorrer sobre a criminologia crítica, desconstrói o mito do direito penal como direito igual, que, segundo ele, 
pode ser resumido em três proposições: a) o direito penal não defende todos os bens essenciais, nos quais igualmente interessados todos os cidadãos, e quando pune as ofensas aos bens essenciais o faz com intensidade desigual e de modo fragmentário; b) a lei penal não é igual para todos, o status de criminosos é distribuído de modo desigual entre os indivíduos; c) o grau efetivo de tutela e a distribuição de status de criminoso é independente da lesividade social das ações e da gravidade das infrações à lei, no sentido de que estas não constituem a variável principal da reação penalizante e da sua intensidade.

Em conclusão, pode-se deduzir que a elite ou classe hegemônica tem a vantagem de se subtrair ao controle das instâncias penais, pois quando os delitos a ela relacionados são efetivamente descritos, é facilmente perceptível que, por assenhorar-se do poder econômico, polínico e de outras espécies, e deter, por conseguinte, prestígio social, tem a garantia material e formal de que não será objeto de investigação ou de qualquer censura judicial, o que alimenta um círculo vicioso de impunidade.

\section{Grupos de pressão e fases legislativas}

Ripollés (2005, p. 21) adverte que, nos momentos distintos da elaboração da lei, desde a sua concepção, agem grupos e atores distintos. Vejamos:

\footnotetext{
a) na fase pré-legislativa, desencadeia-se o processo sociológico decorrente de uma decisão legislativa, tendo por suposto o êxito de um agente social em tornar crível a existência de uma disfunção social que necessita da intervenção estatal, no caso, o Direito Penal, coação máxima relativa ao monopólio legítimo da violência. São determinantes grupos de interesses ou não e, no extremo, grupos de pressão.
}

Nesse sentido, o autor assevera que os agentes sociais que têm aptidão para pôr em marcha o projeto de criação da lei penal podem ser forças políticas, sociais ou econômicas institucionalizadas, como governo, partidos políticos, sindicatos, associações empresariais, corporativas ou profissionais, confissões religiosas oficiais ou semioficiais e, ainda, grupos sociais organizados mas não institucionalizados, como associações de proteção ao meio ambiente, feministas, pacifistas, religiosas, culturais, científicas, de opinião, de vítimas ou de promoção de qualquer interesse. Ou pessoas isoladas, como ensaístas, cientistas, vítimas proeminentes. Além destes, obviamente, os próprios meios de comunicação.

$\mathrm{O}$ único requisito exigido é que sejam capazes de conferir credibilidade a suas apreciações no sentido antes referido. 
b) a fase legislativa, que abarca o conjunto de atuações que tais entes e os parlamentares a eles ligados têm no parlamento, desde o momento em que a Casa recebe o projeto de lei (RIPOLLÉS, 2005, p. 54).

c) a fase pós-legislativa, que é composta por um conjunto de atividades de avaliação dos diversos efeitos da decisão legal após sua entrada em vigor e perdura até o momento em que se questiona se é socialmente plausível sua adequação à realidade social ou econômica que pretende regular. Avalia-se se, a partir das consequências, com maior poder de reflexão, a racionalidade da lei, na verdade uma abordagem pragmática, ou seja, a adesão de seus destinatários. O autor admite que aqui se inicia uma nova fase pré-legislativa (RIPOLLÉS, 2005, p. 62-63)

Interessa-nos, portanto, para os fins deste artigo, a fase pré-legislativa, pois nesse cenário o parlamento sofre um escrutínio social mais acentuado. Entretanto, não há de se descurar, mormente no Brasil, a fase legislativa, em que atuam os chamados lobbies, grupos de pressão que Dortier (2010, p. 257) considera uma reivindicação direta, em defesa de uma causa ou de interesses categoriais junto aos homens políticos, aos serviços administrativos e, no mais alto nível, junto às instâncias governamentais.

Considerado em muitos países uma perversão da democracia, nos Estados Unidos, ao contrário, admite o autor, cuida-se de um componente essencial da vida política nacional. Contudo, reconhece que pode propiciar um diálogo profundo, permitindo ao legislador levar em consideração as preocupações particulares de certos grupos, mas, noutro ângulo, essa cooperação pode gerar situações de pura e simples corrupção (DORTIER, 2010, p. 257).

\section{Grupos de pressão em sentido estrito}

Ripollés (2005, p. 28-33) discorre sobre a opinião pública atuando junto aos meios de comunicação. Nesse contexto, liga a visibilidade, na sociedade, do desajuste social e do malestar que ele cria. Prevalece a formação da opinião pública, surgindo um componente essencialmente argumentativo, determinando-se a agenda temática dos meios, estudo dos meios empregados para ressaltar ou obscurecer ou priorizar certos temas.

Não há que se confundir opinião pública com grupo majoritário da sociedade, nem a totalidade de opiniões existentes sobre o tema, mas a um coletivo qualificado de pessoas, mais concretamente, daquelas que determinam os conteúdos dos meios de comunicação (e, hoje em dia, das tendências mais fortes nas redes sociais). Refere o autor aos redatores, roteiristas ou editores, aos articulistas e comentaristas habituais, assim como todos aqueles que têm capacidade significativa para selecionar as matérias a tratar e para decidir o modo de abordagem e ênfase em relação a elas; e não se pode esquecer dos diferentes setores privados, corporativos, políticos, entre outros que, ao redor desses meios, terminam por condicionar ou influir em seus conteúdos. É certo, porém, que a opinião pública não é um programa de ação. 
Este é qualificado por um estado de opiniões que supera a generalidade da opinião pública. É concreto, portanto tem potencialidade de aprofundar o conhecimento do problema, identificar o objetivo ou objetivos e influenciar na adoção ou abstenção de decisões legislativas, no que se refere ao grupos de pressão especializados que, pela respeitabilidade social, apropriam-se do problema, dispondo de meios materiais e pessoais para se aprofundar na análise e buscas de soluções.

Tais grupos defendem interesses diversos, que podem ser ideológicos, destacando-se os grupos surgidos na sociedade civil, como grupos de pressão feministas, ecologistas, de consumidores, pacifistas, ou os que defendem interesses puramente científicos, reconduzíveis ao surgimento de um determinado paradigma científico-social, como certa corrente criminológica, ou, inclusive, científico natural. Também podem ser interesses socioeconômicos, como sindicatos e associações empresariais, o que é inerente a entes corporativos, como em nosso âmbito as associações judiciais, de funcionários públicos, de funcionários penitenciários, de médicos forenses, etc.

Ripollés (2005, p. 28-33) acentua que fenômeno interessante é a progressiva influência adquirida pela magistratura em detrimento da doutrina jurídica, sendo que esta tem competência e reconhecimento tradicional na formulação da criação de tipos penais ou na sugestão de que o legislador se abstenha de fazê-lo. Anota que há um exemplo espanhol digno de nota, ou seja, um problema de práxis judicial manifestado pela judicatura que desembocou na reforma legal do delito de corrupção de menores do art. 189.3. Importante, também, o fato de um penalista ocupar função de destaque num corpo político para tomada de decisão, denominado fator pessoal.

É citado o não distanciamento manifesto de suas análises e propostas especializadas das preocupações sociais e da opinião pública, dispondo-se de estudos sociológicos sobre diferentes perfis de grupos de pressão a esse respeito.

Importante assinalar o papel dos grupos de pressão da mídia, aduzindo-se que eles antecipam e substituem a intervenção de especialistas.

Bobbio (2010, p. 1040-1041) admite que os meios de informação desempenham uma função determinante para a politização da opinião pública e, nas democracias constitucionais, têm capacidade de exercer um controle sobre os órgãos dos três poderes. A imprensa independente, portanto, enquanto se posiciona em posição de competição corporativa com órgãos do poder público, foi definida como quarto poder. 
[...] Entretanto, atualmente, passada a fase do século de ouro do jornalismo político, a exigência da economia da concentração fez diminuir o número de jornais. O balanço financeiro da empresa jornalística depende muito mais de quem anuncia do que de quem adquire o jornal. Quanto aos meios audiovisuais são muitas vezes do Governo ou por ele controlados. Logo, não há mais falar-se em quarto poder, no caso (BOBBIO, 2010, p. 1040-1041).

Com o tempo, modificou-se o ponto de vista de que a opinião pública fosse incapaz de compor um grupo de ação, pois, com efeito, houve um progressivo incremento da função social dos meios de comunicação que passam a ser considerados especializados para todos os efeitos e com uma polivalência desconhecida nos grupos de pressão propriamente ditos.

Entretanto, isso não é interessante, pois há outorga da hegemonia em quase toda fase pré-legislativa a um único agente social. O grupo de pressão da mídia, dada sua capacidade de influenciar na primeira etapa do desajuste social, desempenha um papel significativo na etapa subsequente, concernente ao aparecimento do mal-estar social e cabe a ele a divulgação do desajuste social, podendo grupos políticos e parlamentares influenciar no conteúdo da opinião pública, condicionando o fluxo, seja através do controle direto ou indireto dos meios.

Também é comentado o protagonismo da plebe, sendo ilustrado o caso de grupo de vítimas que, nos Estados Unidos, país em que os exemplos são abundantes, como o caso californiano da lei chamada "na terceira você está perdido" (three strikes and you're out) que constitui, basicamente, na neutralização do indivíduo que comente um terceiro delito. A lei foi redigida e assinada por um fotógrafo, pai de vítima de assassinato e membro de um grupo de vítimas. Em síntese, a lei estabelece que, após o cometimento de um terceiro delito (felony) qualquer, uma pessoa deve ser obrigatoriamente condenada a uma pena efetiva de 25 anos de prisão perpétua (em sentido estrito), sem liberdade provisória antes que sejam cumpridos $80 \%$ do tempo total da referida pena.

Não bastasse isso, o cometimento de um segundo delito qualquer já acarreta a duplicidade de pena prevista para essa infração, não sendo preciso que os delitos sejam violentos, importando apenas que sejam graves. Em que pese isso, a iniciativa ficou fora da agenda até que uma jovem de 12 anos fosse raptada de sua própria casa e estuprada, assunto que recebeu cobertura midiática ao longo do mês.

Chamou atenção o fato de que não houve negligência por parte de ninguém e que se tratava de uma pessoa pertencente a uma família de classe média, por ser autor do crime um reincidente em delitos violentos e por estar em liberdade condicional. Na iminência de eleições para governador, nas quais era candidato o ocupante do cargo, um republicano com uma assembleia dominada por democratas, esta acolheu a chamada do governador, elaborando cinco alternativas para combater reincidentes, compondo a lista a proposta de Reynolds, o fotógrafo, 
coincidentemente a mais dura. A assembleia não escolheu nenhuma, comprometendo-se a aprovar a que o governador apontasse. O governador, no cálculo político, escolheu a de Reynolds, recusando uma proposta mais matizada da Associação de Promotores da Califórnia, e, assim, a proposta do fotógrafo foi aprovada pela Assembleia Legislativa, em março de 1994.

Posteriormente, a proposta, que já era lei, foi submetida a referendo por iniciativa popular em novembro de 1994, ocasião em que, ao ganhar a votação, os grupos de vítimas e seus defensores conseguiram mais uma vitória, determinando ao Legislativo a manutenção da lei e um adicional, determinando que a Assembleia não poderia modificá-la sem apoio mínimo de 2/3 das duas Câmaras.

\section{Casos práticos de grupos de pressão no Brasil}

Podemos elencar vários casos em que grupos de pressão atuaram na elaboração da lei penal no Brasil ou na abstenção de sua aplicação, ora obtendo êxito, ora não sendo atendidos nos seus pleitos.

Casos relacionados à magistratura, ou órgãos quase judiciais, podem ser elencados. Vejamos:

\section{Comissões ou Cortes Transnacionais e Justiça Nacional}

a) desacato. Conforme leciona Ramos (2019), em 2016, a $5^{\text {a }}$ Turma do Superior Tribunal de Justiça afastou a tipicidade do crime de desacato. No voto do Rel. Min. Ribeiro Dantas, fezse necessário exercitar o controle da convencionalidade das leis brasileiras, isto é, levar em consideração a interpretação da Comissão Interamericana de Direitos Humanos e da Corte Interamericana de Direitos Humanos. No voto, esclareceu-se que as recomendações da Comissão assumem força normativa interna, em conformidade com precedente da Corte, especialmente no caso Loyaza Tamoyou vs Peru, pautando-se, ainda, no princípio da boa-fé, consagrado também na Convenção de Viena sobre Direito dos Tratados. Entretanto, em 2017, a Terceira Seção do Superior Tribunal de Justiça considerou constitucional e convencional o desacato. A parte vencedora entendeu, dentre outros fundamentos, que a posição da Comissão de Direitos Humanos não é vinculante, sendo mera recomendação. Quanto aos demais casos julgados pela Corte Interamericana de Direitos Humanos, não se tratava de desacato, mas casos envolvendo liberdade de expressão e crítica. Em 2018, a $2^{\text {a }}$ Turma do STF considerou compatível com a Constituição e com a Convenção Interamericana de 
Direitos Humanos o crime de desacato a militar (art. 299 do Código Penal Militar).

b) a Comissão Interamericana de Direitos Humanos, ao receber denúncia relativa à violência doméstica praticada contra a Sra. Maria da Penha Fernandes, no Relatório 54/01, caso 12.051, decidiu pela admissibilidade do pleito, recomendando ao Brasil a concluir ao procedimento penal instaurado, indenizar a vítima pela demora no julgamento do processo. A recomendação da Comissão salientava que o Brasil deveria adotar medidas legislativas que protegessem a mulher contra a violência, vindo a lume a Lei $n^{0} 11.340 / 2006$, que cuida da violência doméstica.

c) prisão por dívida. O Supremo Tribunal Federal proibiu a prisão por dívida, tanto na hipótese de depósito como em relação à alienação fiduciária. Entendeu a Corte Suprema que a lei brasileira violou o artigo $7^{\circ}, 7-7$. "Ninguém deve ser detido por dívidas", contido na Convenção Interamericana de Direitos Humanos. A única exceção seria a prisão do alimentante que, podendo prestar alimentos, decide voluntariamente não os prestar. Segundo Ramos (2019), para o STF o status normativo supralegal ou constitucional dos tratados de direitos humanos, no Brasil, tornou inaplicável a legislação ordinária ou mesmo complementar com eles conflitantes, anterior ou posterior à ratificação do Tratado (RE466.343, rel. Min. Cezar Peluso, voto do Min. Gilmar Mendes, j. 3-12-2008, Plenário, DJe de 5-6-2009, com repercussão geral). A decisão resultou na edição da Súmula Vinculante $n^{\circ}$ 25 , no sentido de que "é ilícita a prisão civil de depositário infiel, qualquer que seja a modalidade de depósito".

d) a Corte Interamericana de Direitos Humanos decidiu que o crime de redução à condição análoga a de escravo é imprescritível. A sentença foi emitida em desfavor do Brasil, responsabilizando-o internacionalmente por não garantir a proteção de dezenas de trabalhadores rurais para a execução de diversos trabalhos, na propriedade pecuária Brasil Verde. O caso chegou à Comissão Interamericana de Direitos Humanos, em 1998, em razão do acionamento efetivado pela Comissão Pastoral da Terra e o Centro pela Justiça e o Direito Internacional. Em 2015, em face das reiteradas violações aos direitos humanos relativos aos mesmos agentes e diante da inércia do Estado brasileiro, a Comissão submeteu o caso à Corte Interamericana de Direitos Humanos e, em 2016, a CIDH considerou o Estado brasileiro como responsável. Além da condenação à indenização das vítimas, a Corte ordenou a reabertura das investigações, dado que compreendeu que o crime em questão é imprescritível. A investigação foi reaberta e os investigados impetraram habeas corpus junto ao TRF-1 ${ }^{\mathrm{a}}$ Região, pugnando pela prescrição da pretensão punitiva. Todavia, o Tribunal entendeu que a prescrição penal é material legal, ao passo que os tratados têm caráter 
supralegal, decorrendo daí a licitude na continuação do inquérito policial. A reação do Poder Legislativo foi a de elaborar uma Proposta de Emenda à Constituição no 14, de 2017, em que se considera imprescritível a prática do crime de redução à condição análoga a de escravo.

e) a Procuradoria Federal dos Direitos do Cidadão, órgão do Ministério Público Federal, ofereceu parecer na Arguição de Descumprimento de Direito Fundamental, no 442, ajuizada perante o Supremo Tribunal Federal, pelo Partido Socialismo e Liberdade, para que se declare a não recepção dos arts. 124 e 126 do Código Penal, relacionados à criminalização do aborto no Brasil. A ação de índole constitucional encontra-se pendente de julgamento. Conforme se verá abaixo, em razão de proposta de projetos criminalizando a conduta, hipotética procedência da ação poderá resultar no denominado efeito political backlash. $\mathrm{O}$ pedido formulado na ação está ventilado no seguinte sentido: “declare a não recepção parcial dos arts. 124 e 126 do Código Penal, para excluir do seu âmbito de incidência a interrupção da gestação induzida e voluntária realizada nas primeiras 12 semanas, por serem incompatíveis com a dignidade da pessoa humana e a cidadania das mulheres e a promoção da não discriminação como princípios fundamentais da República, e por violarem direitos fundamentais das mulheres à vida, à liberdade, à integridade física e psicológica, à igualdade de gênero, à proibição de tortura ou tratamento desumano ou degradante, à saúde e ao planejamento familiar, de modo a garantir às mulheres o direito constitucional de interromper a gestação, de acordo com a autonomia delas, sem necessidade de qualquer forma de permissão específica do Estado, bem como garantir aos profissionais de saúde o direito de realizar o procedimento".

\section{II.Casos no Brasil}

a) projeto de lei apresentado pelo Senador Pedro Taques, de $n^{\circ} 5.900 / 2013$, que altera o art. $1^{\circ}$ da Lei $n^{\circ}$ 8.072, de 25 de julho de 1990 (Lei dos Crimes Hediondos), para prever os delitos de peculato, concussão, excesso de exação, corrupção passiva e corrupção ativa, além de homicídio simples e suas formas qualificadas, como crimes hediondos; e altera os arts. 312 , 316, 317 e 333 do Decreto-Lei no 2.848, de 7 de dezembro de 1940 (Código Penal), para aumentar a pena dos delitos neles previstos (BRASIL, 2013). O projeto de lei, apresentado em 2013, encontra-se, ainda, na Casa Legislativa em que foi dada iniciativa ao projeto. Tratase de um projeto que tem como destinatários agentes políticos e públicos, além de terceiros envolvidos em crimes de corrupção.

b) a lei Daniella Perez foi o primeiro projeto de lei apresentado por iniciativa popular no Brasil, 
impulsionado pela forte campanha de combate à impunidade iniciada pela mãe da vítima, que é famosa como dramaturga, e resultou, após intensa e quase imediata tramitação parlamentar que envolveu até o Executivo federal, na atribuição do status de crime hediondo aos crimes de homicídio qualificado e de homicídio praticado em atividade típica de grupo de extermínio. A lei foi sancionada em 1994, ano eleitoral, e serve como exemplo da atuação de um coletivo de vítimas como grupo de pressão, nos moldes do presente estudo (PAIVA, 2009, p. 134-135).

c) nomeada pelo Ministério da Justiça, uma comissão de juristas elaborou o projeto de lei para tratamento dos Crimes de especial gravidade que, com intuito de rediscutir a lei dos crimes hediondos, garantia o sistema progressivo da pena, apesar de manter o tratamento penal mais rigoroso. Após longa tramitação e tratamento intensivo e violento da imprensa, em especial na fase final, o projeto foi arquivado em 2001 (PAIVA, 2009, p. 137-139).

d) a célebre lei da falsificação de remédios, de 1998, que tem origem no caso amplamente noticiado de criança que veio a óbito após a manipulação com antibiótico falsificado no Rio de Janeiro, é outro exemplo da ação das vítimas como grupo de pressão, aliadas à mídia. Era o sétimo caso identificado de falsificação de remédios no estado do Rio de Janeiro. Somado a este fato, em 1998, houve o desvio de milhares de placebos de uma multinacional farmacêutica que provocou a colocação no mercado de falsos anticoncepcionais, resultando na gravidez de 189 mulheres. Em menos de dois meses do ocorrido, já se havia apresentado a primeira proposta legislativa tipificando a conduta de adulteração e falsificação de remédios e alimentos. Em julho de 1998, o Executivo Federal enviou ao Congresso Nacional a proposta de agravamento das penas e alteração dos tipos dos crimes contra a saúde pública (PAIVA, 2009, p. 140-141). Trata-se, como se vê, de um projeto derivado de um caso criminoso cujo projeto de lei inspirou-se nos esforços de vítima proeminente, tal qual o de Reynolds nos EUA, acima relatado.

e) Projeto de Lei $n^{\circ}$ 6.438/2019 que Altera a Lei ${ }^{0}$ 10.826, de 22 de dezembro de 2003, que dispõe sobre registro, posse e comercialização de armas de fogo e munição, sobre o Sistema Nacional de Armas (SINARM) e define crimes, e dá outras providências. Esse projeto, aliado ao Projeto de Lei $n^{\circ} 3.723 / 2019$, afrouxam as amarras previstas no Estatuto do Desarmamento. Complementarmente, há de ser lembrado o projeto de Lei $n^{\circ} 5.417 / 2020$, que estabelece normas para publicidade de armas de fogo em todo território nacional e dá outras providências.

f) Projeto de Lei no 6.125/2019, que "Estabelece normas aplicáveis aos militares em operações de Garantia da Lei e da Ordem e aos integrantes dos órgãos a que se refere o caput do art. 
144 da Constituição e da Força Nacional de Segurança Pública, quando em apoio a operações de Garantia da Lei e da Ordem". O projeto, em seu art. $2^{\circ}$, dispõe sobre a legítima defesa em favor de militar ou agente de segurança pública em operações de garantia da lei e da ordem.

g) $\operatorname{PEC~n}$ o 32/2019, que "Estabelece a responsabilidade penal aos maiores de 16 (dezesseis) anos de idade na hipótese de cometimento de crimes previstos na legislação e, em se tratando de crimes definidos como hediondos, tráfico ilícito de entorpecentes e drogas afins, terrorismo, organização criminosa e associação criminosa, a partir de 14 (quatorze) anos de idade".

h) Projeto de Lei $n^{\circ} 478 / 2007$, que "Dispõe sobre o Estatuto do Nascituro e dá outras providências." O projeto é defendido pelo Executivo e vai de encontro com a ADPF 442, acima mencionada e tido, no presente artigo, como uma possibilidade de backlash caso a ação seja julgada procedente antes da sanção do projeto de lei.

\section{Conclusão}

Compreendidos os moldes da atuação dos grupos de pressão no processo legislativo brasileiro, tanto em teoria quanto em seu aspecto empírico, observa-se, inevitavelmente, a existência de um recorte de classe e de interesse evidente, ainda mais latente nos exemplos postos à mostra, sendo possível até mesmo afirmar que se trata da parcela que, dentre todos os grupos de interesse na sociedade, atinge seus objetivos e transforma seus interesses em leis e, na sequência, em políticas públicas efetivadas.

Não poderia ser diferente para o Direito Penal, sendo, então, que, para a matéria, os grupos de pressão são atores igualmente ou mais obstinados que para os outros campos da ciência jurídica, em razão do alto potencial de impacto na sociedade que o tratamento das relações sociais, pela via penal, possui, em comparação com as demais formas de se promover a tutela jurídica de condutas socialmente relevantes. Aqui, também, transparece o recorte de classe aludido, quando se percebe que aqueles que praticam delitos têm diferentes destinos e se encontram em discrepantes proporções no sistema penal vigente no Brasil, de acordo com a sua origem econômica, social, geográfica e étnica.

Da análise dos casos de atuação dos grupos de pressão narrados e analisados na segunda metade deste artigo, nota-se que é inegável a relação entre os encaminhamentos das proposições legislativas e das políticas públicas e os interesses promovidos pelos grupos de pressão capazes de acessar e impactar a mentalidade e as atividades do Poder Legislativo, assim como que nem 
sempre o aludido interesse reflete verdadeiras melhorias em benefício da sociedade de modo sistêmico, mas, por vezes, contempla interesses de um estrato menor, porém mais privilegiado, em detrimento dos demais e sem necessariamente buscar equilibrar os benefícios e ônus das situações jurídicas tuteladas.

Dessa sorte, se o processo legislativo deveria seguir o Direito de modo generalizado em seu objetivo de promover a pacificação social, e o Estado na sua função de buscar o bem-estar comum, o processo legislativo no Brasil - e quiçá na maior parte do mundo —, na contramão do que preconizam os teóricos clássicos, não alcança a todos, assim como não atende a todos os grupos de interesse, cedendo à pressão de apenas uma seleta e privilegiada parcela desses grupos.

Com efeito, conclui-se que, com relação aos crimes praticados pela classe política ou por pessoas de origem socioeconômica privilegiada, a ação dos grupos de pressão tem efeitos minimizados, senão nulos, no processo legislativo brasileiro. O que se conclui é que esses grupos de interesse só atuam com efetividade na pressão que exercem para impulsionar medida punitivas que, em última análise, somente se aplicam à parcela desprivilegiada da população.

\section{Referências}

BARATTA, Alessandro. Criminologia crítica e crítica do direito penal: introdução à sociologia do direito penal. 3. ed. Tradução de Juarez Cirino dos Santos. Rio de Janeiro: Editora Revan: Instituto Carioca de Criminologia, 2002.

BERGALLI, Roberto; BUSTOS, Juan; MIRALLES, Teresa. O pensamento criminológico I: uma análise crítica. Tradução de Roberta Duboc Pedrinha, Sergio Chastinet Duarte Guimarães. Rio de Janeiro: Renavan, 2015.

BOBBIO, Norberto et al. Dicionário de política. 13. ed. Tradução de Carmen C. Varriale et al.; coord. Trad. João Ferreira; rev. geral João Ferreira e Luis Guerreiro Pinto Cacais. Brasília: Editora Universidade de Brasília, 2010, v. 1.

BRASIL. Câmara dos Deputados. PL 5900/2013. Senado Federal - Pedro Taques - PDT/MT. Altera o art. $1^{\circ}$ da Lei no 8.072, de 25 de julho de 1990 (Lei dos Crimes Hediondos), para prever os delitos de peculato, concussão, excesso de exação, corrupção passiva e corrupção ativa, além de homicídio simples e suas formas qualificadas, como crimes hediondos; e altera os arts. 312, 316, 317 e 333 do Decreto-Lei no 2.848, de 7 de dezembro de 1940 (Código Penal), para aumentar a pena dos delitos neles previstos. Disponível em: https://www.camara.leg.br/proposicoesWeb/fichadetramitacao?idProposicao=583945 Acesso em: 19 jun. 2021.

CARRARA, Francesco. Programa do curso de direito criminal - parte geral. Tradução de Ricardo Rodrigues Gama. Campinas: LZN Editora, 2002, v. I. 
COENEN-HUTHER, Jacques. Sociologia das elites. Tradução de Ana Paula e Luíz Viveiros. Lisboa: Instituto Piaget, 2004.

DORTIER, Jean-françois (diretor). Dicionário de ciências humanas. rev. e coord. da tradução Márcia Valéria Martinez de Aguiar. São Paulo: Editora Martins Fontes, 2010.

PAIVA, Luiz Guilherme de. A fábrica de pena: racionalidade legislativa e a lei dos crimes hediondos. Rio de Janeiro: Revan, 2009.

PEREIRA, Paulo Trigo. Governabilidade, grupos de pressão e o papel do Estado. Instituto Superior de Economia e Gestão Universidade Técnica de Lisboa. I Encontro Nacional de Ciência Política, Fundação Calouste Gulbenkian, dez. 1999. Disponível em:

https://doczz.com.br/doc/608842/governabilidade--grupos-de-press\%C3\%A3o-e-o-papel-doestado Acesso em: 19 jun. 2021.

PERISSINOTTO, Renato. As elites políticas, questões de teoria e método. Curitiba: Ibpex. 2009.

RAMOS, André de Carvalho. Curso de direitos humanos. São Paulo: Editora Saraiva, 2019.

RIPOLLÉS, José Luis Díez. A racionalidade das leis penais: teoria e prática. Tradução de Luiz Regis Prado. São Paulo: Editora Revista dos Tribunais, 2005.

SANTOS, Juarez Cirino dos. Direito Penal: parte geral. 21. ed. Curitiba: ICPC; Lumen Juris, 2006. 